\title{
Ortaokul Öğrencilerinin Fen Bilimleri ve Matematik Dersine Katılım Düzeylerinin Belirlenmesi ve Çeşitli Değişkenler Açısından İncelenmesi ${ }^{1 *}$
}

\author{
Selçuk FIRAT \\ Dr. Öğr. Üyesi, Adıyaman Üniversitesi, \\ Eğitim Fakültesi, Eğitim Bilimleri Bölümü \\ selcukfirat@adiyaman.edu.tr \\ Orcid ID: https://orcid.org/0000-0002-2935-2929
}

\author{
Esra AÇIKGÜL FIRAT \\ Dr. Öğr. Üyesi, Adıyaman Üniversitesi, \\ Eğitim Fakültesi, Matematik ve Fen Bilimleri Eğitimi Bölümü \\ eacikgul@adiyaman.edu.tr \\ Orcid ID: https://orcid.org/0000-0002-6401-1476
}

\begin{abstract}
Öz
$\mathrm{Bu}$ çalışmada ortaokul öğrencilerinin fen bilimleri ve matematik derslerine katılım düzeylerini belirlemek ve bazı değişkenler açısından incelemek amaçlanmıştır. Araştırma, nicel araştırma yöntemlerinden tekil tarama ve nedensel-karşılaştırma araştırma desenleri kullanılarak yürütülmüştür. Araştırmada veri toplama aracı olarak Fen Bilimleri ve Matematik Derslerine Katılım Ölçeği kullanılmıştır. Bu ölçek öğrenci katılımını; duyuşsal katılım, bilişsel katılım, davranışsal katılım ve sosyal katılım boyutlarında çok boyutlu olarak ölçmektedir. Araştırmadan elde edilen sonuçlara göre ortaokul öğrencilerinin fen bilimleri ve matematik derslerine katılım düzeylerinin yüksek olduğu belirlenmiştir. Ayrıca hem fen bilimleri hem de matematik derslerinde öğrencilerin duyuşsal katılım, bilişsel katılım, davranışsal katılım ve sosyal katılımlarında cinsiyet açısından kızların lehine anlamlı bir farklılık olduğu belirlenmiştir. Araştırmadan elde edilen diğer bir sonuç ise proje tasarlama konusunda kendilerini yeterli gören öğrencilerin duyuşsal katılım, bilişsel katılım, davranışsal katılımlarının anlamlı bir şekilde diğer öğrencilere göre yüksek olduğu belirlenmiştir.
\end{abstract}

\footnotetext{
${ }^{1}$ Makale Geliş/Kabul Tarihi: 10.08.2020 / 24.04.2021

* Bu çalışma, 6. Uluslararası Bilimsel Araştırmalar Kongresi'nde sözlü bildiri olarak sunulmuştur.

Künye Bilgisi: Fırat, S. ve Açıkgül Fırat, E. (2021). Ortaokul öğrencilerinin fen bilimleri ve matematik dersine katılım düzeylerinin belirlenmesi ve çeşitli değiş̧enler açısından incelenmesi. Kahramanmaraş Sütçü İmam Üniversitesi Sosyal Bilimler Dergisi, 18(1), 72-88. DOI: $10.33437 / \mathrm{ksusbd} .778651$
} 
$\underline{\text { S. Fırat-E. Acıkgül Fırat } \quad \text { Ortaokul Öğrencilerinin Fen Bilimleri ve... }}$

Anahtar Kelimeler: Öğrenci Katılımı, Ortaokul Öğrencileri, Fen Bilimleri Eğitimi, Matematik Eğitimi.

\title{
Determination of Secondary School Students' Science and Maths Engagement Levels and Investigation in Terms of Various Variables
}

\begin{abstract}
This study aimed to determine the engagement levels of secondary school students in science and mathematics classes and to examine them in terms of some variables. The research was carried out by using descriptive and causalcomparative research methods. In the research, The Math and Science Engagement Scales were used as data collection tool. This scale includes student engagement; cognitive engagement, behavioral engagement, social participation, and emotional engagement. According to the results obtained from the study, it was determined that secondary school students' engagement levels in science and maths lessons were high. In addition, it was determined that there is a significant difference in favor of girls in terms of gender in terms of engagement levels of students in both science and maths lessons. Another result obtained from the study is that students who consider themselves competent in designing projects in dimensions of cognitive engagement, behavioral engagement, and emotional engagement, have higher engagement at significant level.
\end{abstract}

Keywords: Student Engagement, Secondary School Students, Science Education, Maths Education.

\section{GİRIŞ}

Öğrenci katılımı, öğrenme sürecindeki önemi nedeni ile uzun yıllardır üzerinde çalışmalar yapılan bir konudur. Çünkü, öğretim sürecine ne kadar fazla öğrenci katılırsa ve özgüvenli davranırsa bu enerjilerini öğrenmelerine de yönlendirme olasıllkları da o kadar artmakta ve bu durum kısa ve uzun vadeli sonuçlar yaratmaktadır (Bond vd., 2020:3). Dolayısıyla, öğrenci katılımı ifadesi, öğrencilerin öğretim sürecine ne kadar dahil olduklarına veya süreçte ne kadar ilgili göründüklerine ve sınıflarına, kurumlarına, birbirlerine ne kadar bağlı olduklarına işaret etmektedir (Axelson and Flick, 2010:38). Araştırmalar da öğrencilerin kendi öğrenmelerine katıldıklarında öğrenme süreçlerinde artan motivasyon ve başarı dahil olmak üzere çok çeşitli faydaların ortaya çıktığını göstermektedir (Sinatra vd., 2015:1). Böylelikle öğrenci katılımı, öncelikle başarıya, olumlu davranışlara ve okulda kalabilmeleri için öğrencilerde aidiyet duygusunu artırmaya odaklanmıştır (Taylor and Parsons 2011:4). Mevcut araştırmalar da katılımın öğrenme için kritik olduğunu ve katılımın okul 
başarısını sağladığını ortaya koymaktadır (Rimm-Kaufman vd., 2015:2). Bu nedenle öğrenci katılımı, eğitim psikolojisi alanındaki popüler araştırma konularından biri haline gelmiştir ve araştırmalar, öğrencilerin kendi öğrenme süreçlerine katıldıklarında motivasyon ve başarılarının artması da dahil olmak üzere çok yönlü faydalarının ortaya çıktığını göstermektedir (Sinatra vd., 2015).

Eğitimde katılım kavramının önemine rağmen hem kavramsallaştırılması hem de ölçümü ile ilgili zorluklar bulunmaktadır ve bu konuda araştırmacılar arasında fikir ayrılıkları yaşanmaktadır (Sinatra vd., 2015:1). Genel olarak kullanılan katılım tanımı, "akademik çalışmanın teşvik etmeyi amaçladığı bilgi, beceri veya el sanatlarını öğrenme, anlama veya ustalaşmaya yönelik psikolojik yatırım ve çaba" dır (Newmann vd., 1992; akt. Mo vd., 2013:5). Öğrencilerin sınıf etkinliklerine katılımı ise insan ihtiyaçları, duygu, niyet, motivasyon, ilgi alanları, kimlik gibi faktörlerin bir fonksiyonu olarak tanımlanmaktadır (Azevedo vd., 2012:270). Araştırmalar öğrencilerin öğretmenleri ve akranlarıyla güçlü ilişkiler geliştirdiği sınıflarda katılımın daha yüksek olduğunu göstermektedir; bu sınıflar öğretmenlerin öğrencilerinin özerkliğini destekledikleri, tutarl, net geri bildirim verdikleri, görevlerin değişken, zorlu, ilginç ve anlamlı olduğu yerlerdir (Fredricks, 2011:330). Dolayısıyla, öğrenci katılımını etkileyen birçok faktör bulunmaktadır. DeVito (2016:1), öğrenci-öğretmen etkileşimi, öğretmen davranışı, öğretim stili, sınıf yönetimi, öğretmenin kişilik özellikleri ve akranlar, aile katılımı, öğrenme topluluğu, öğrencinin sosyo-ekonomik düzeyi gibi faktörlerin öğrenci katılımını etkilediğini belirtmiştir.

Öğrenci katılımı oldukça karmaşık ve çok yönlü bir yapıdadır (Fielding-Wells and Katie Makar, 2008). Katılımın nasıl tanımlandığı ve çalışıldığı konusunda büyük farklılıklar olmasına rağmen, katılımın çok boyutlu bir yapı olduğu konusunda uzlaşmalar bulunmaktadır (Fredricks vd., 2016b:4). Birçok çalışma öğrencilerin genel katılımını incelemiş olsa da bazı çalışmalar katılımın farklı boyutlarını dikkate almıştır. Bu tutarsızlıklara rağmen, literatürde öğrenci katılımının çok boyutlu bir yapı olduğu konusunda geniş bir uzlaşma vardır, ancak hem boyut sayısında (2'den 4'e kadar) hem de her boyutun göstergelerinde farkl11ıklar bulunmaktadır (Fredricks vd., 2016a:1). Akademik literatürde en yaygın kavramsallaştırma, katılımın davranışsal, duyuşsal ve bilişsel katılım olmak üzere birbiriyle ilişkili üç ayrı boyuttan oluşmasıdır (Fielding-Wells ve Makar, 2008; Fredricks vd., 2004:59). Davranışsal, duygusal ve bilişsel katılım öğrenme ortamlarının yapısına verilen tepkilerdir (Sinatra vd., 2015:3). Öğrenciler öğrenme sürecinde bu boyutlardan sadece biri ile katılım gerçekleştirmezler, birden çok boyutta katılım sergileyebilirler. Örneğin, oldukça ilginç ancak karmaşık bir problemi tamamlamak için özenle çalışan bir öğrenci davranışsal olarak bu problemle uğraşabilir ve aynı zamanda oldukça etkili bir şekilde bilişsel olarak katılım sağlayabilir (Fielding-Wells and Makar, 2008). Bununla birlikte, birden çok basit ve sıradan algoritma üzerinde çalışan bir 
$\underline{\text { S. Fırat-E. Acıkgül Fırat } \quad \text { Ortaokul Öğrencilerinin Fen Bilimleri ve... }}$

öğrenci davranışsal olarak katılım sağlayabilir ancak sıkılmış, hayal kırıklığına uğramış ve zihinsel olarak aktif katılım sağlamamış olabilir (Fielding-Wells and Makar, 2008).

Birçok eğitmenin ve araştırmacının amacı, öğrencileri davranışsal katılım olarak bilinen kendi öğrenme süreçlerindeki eylemlere katılmaya motive etmektir (Sinatra vd., 2015:2). Bazı çalışmalar fen bilimleri dersinde de temel olarak davranışsal katılımı vurgulamışlardır (Mo vd., 2013:5). Davranışsal katılım, dikkat gösterme, verilen işi tamamlama, öğretmen onaylı öğrenme firsatlarına katılma ve zarar verici davranışların bulunmaması anlamına gelmektedir (RimmKaufman vd., 2015:2). Literatürde davranışsal katılım, katılım, çaba, dikkat, sebat, olumlu davranış ve zarar verici davranışın yokluğu olarak açıklanmıştır (Fredricks vd., 2004). Fen bilimleri öğreniminde davranışsal katılım ise fen ödevlerinin tamamlanması, fen dersine ve deneylere katılım ve ekstra çalışma yapılmas1 olarak tanımlanabilir (Mo vd., 2013:5). Fredricks vd. (2004) katılımın bilişsel bir boyutunun da olduğunu belirtmişlerdir. Bilişsel katılımı kesin olarak tanımlamak daha zordur ve tanım yapılamamasının nedeni bilim adamları arasında bilişsel katılımın nasıl faaliyete geçirilmesi gerektiği konusunda mutabakat olmamasıdır (Sinatra vd., 2015:3). Bilişsel katılım, özdenetim, stratejik düşünme ve psikolojik yatırım üzerine odaklanmaktadır (Fredricks vd., 2004:64). Rimm-Kaufman vd., (2015:2)'e göre bilişsel katılım içeriği anlama, zor sorunlarla uğraşma, dikkatlerini yönetme ve eldeki göreve yönlendirme çabası için istekli olma anlamına gelmektedir. Fredricks vd. (2016a:2) ise bilişsel katılımı öğrencinin öğrenmeye yatırım düzeyi olarak tanımlamışlardır. Bilişsel katılım, öğrencilerin bilgiye katılma, hafizalarında bilgi saklama, bilgiye erişim ve bu bilgiyi problemleri çözmek için kullanma şeklini içermesi olarak düşünülebilir (Fielding-Wells and Makar, 2008).

Katılımın diğer bir boyutu olan duygusal katılım ise fene karşı bir ilgi duyma ve etkiye sahip olma olarak tanımlanabilir (Mo vd., 2013:5). Duygusal katılım, içerikle bağlantı duyguları, öğrenmeye ilgi duymayı, sorun çözme ve içerik hakkında düşünme durumlarını ifade etmektedir (Fredricks vd., 2004:60). Okullaşma bağlamında, duygusal katılım öğrencilerin yaşadığı inançlar, tutumlar ve duygular olarak düşünülebilir (Fielding-Wells and Makar, 2008). Dolayısıyla öğrenmeye, öğrenme sürecinde çaba göstermeye istekli olmayı içermektedir. Duyguların devre dışı bırakılması, bir öğrencinin odaktan uzaklaşmasına ve malzeme veya bağlamdan ayrilmasına neden olabilir (Sinatra vd., 2015:3). Son zamanlarda, bazı akademisyenler katılım kavramlarına sosyal etkileşimlerin öğrenmede giderek artan rolünü yansıtmak için sosyal bir boyut eklemişlerdir (Fredricks vd., 2016a:2). Öğrenme sürecinde dördüncü bir yapı olan sosyal katılımın da esas olduğu belirtilmektedir (Rimm-Kaufman vd., 2015:3). Dolayısıyla katılım kavramı çok boyutlu bir yapıya sahiptir ve öğrenci katılımının çok boyutlu olarak incelenmesi gerekmektedir. 


\section{Araştırmanın Gerekçesi}

Öğrencilerin aktif katılımı eğitimde öğrenci başarısı için kritik öneme sahiptir (Wang and Holcombe, 2010; Wang and Eccles, 2013). Başarıda katılımın rolünü destekleyen çalışmalara rağmen, ne tür faaliyetlerin ve değişkenlerin katılım ve başarıya yol açtığı belirsizliğini korumaktadır (Mo vd., 2013:3). Dolayısıyla öğrencilerin katılımını teşvik etmek için, öncelikle katılımı etkileyen faktörleri daha iyi anlamak gerekmektedir (Wang and Eccles, 2013:12). Ayrıca yapılan çalışmalardaki bir başka endişe de çalışmalarda belirlenen önlemlerin çoğunun, belirli konu alanlarına katılım yerine okuldaki genel bağlılığa odaklanmasıdır (Fredricks vd., 2016a:2). Genellikle çalışmalar alana özgü değil de genel öğrenci katılımının belirlenmesi amacı ile yapılmaktadır (Yıldırım vd., 2018). Bu çalışma ile ortaokul öğrencilerinin matematik ve fen bilimleri alanlarına katılımları belirlenerek bu alanlara özgü literatüre katkıda bulunmak amaçlanmıştır. Çünkü, matematik ve fen bilimlerinde öğrenci katılımı, öğrencilerin akademik başarısı ve fen, teknoloji, mühendislik ve matematik (STEM) derslerine ve kariyerlerine uzun vadeli katılımları için hayati önem taşımaktadır (Fredricks vd., 2016a:1). Dolayısıyla öğrencilerin fen ve matematik derslerinde öğretim sürecine aktif katılımı önemli görülmektedir. Bybee (2013) de STEM okuryazarlığını tanımlarken yapıcı, ilgili ve yansıtıcı bir vatandaş olarak STEM ile ilgili konulara ve fen, teknoloji, mühendislik- matematik alanlarına katılım vurgusu yapmıştır (Bybee, 2013). Dolayısıyla Türkiye'de fen bilimleri ve matematik dersleri ögretim programlarına 2018 yılında yapılan değişikler (MEB, 2018) ile entegre edilen STEM'deki başarısı açısından da öğrencilerin fen ve matematik derslerine katılımlarının ve katılımlarını etkileyen faktörlerin belirlenmesi önemli görülmektedir. Fakat yapılan çalışmalar incelendiğinde öğrenci katılımını fen bilimleri ve matematik derslerine özgü ve çok boyutlu olarak inceleyen çalışmaların az olduğu görülmektedir (Fredricks vd., 2016a; Uekawa vd., 2007; Yerdelen-Damar vd., 2020). Bu nedenle fen ve matematik derslerinde öğrenci katılımının çok boyutlu olarak araştırılması önemli görülmektedir.

Uekawa vd. (2007), çalışmalarında öğrencilerin günlük matematik ve fen bilgisi derslerinde sınıf deneyimleri hakkında bilgi kaydetmelerine olanak tanıyan bir sistem ile öğrenci katılım düzeylerini ölçmüşler ve öğrenci katılımı ile bir dizi faktör arasındaki ilişkileri incelemişlerdir. Yapılan çalışmalar incelendiğinde Türkiye'de de fen bilimleri ve matematik alanlarına öğrenci katılımını belirlemek amacıyla yapılan ölçek uyarlama çalışmaları olmasına rağmen (Turan Gürbüz vd., 2020; Yerdelen-Damar vd., 2020) bu alanlarda öğrenci katılımını belirleyen ve katılımı etkileyen değişkenleri inceleyen çalışmaya rastlanmıştır. Ancak Türkiyede'de gerçekleştirilen TIMMS sınavları fen bilimleri ve matematik derslerinde öğrenci katılımlarını, başarı ve okul faktörlerini ölçmektedir. TIMSS 2011'den elde edilen verileri kullanarak, Türkiye'deki ilkokul ve ortaokul öğrencilerinin fen başarısını ve fen bilimlerine 
$\underline{\text { S. Fırat-E. Acıkgül Fırat } \quad \text { Ortaokul Öğrencilerinin Fen Bilimleri ve... }}$

katılımını incelemeyi amaçlayan bir çalışmada öğrencilerin başarı ve katılım boyutları arasındaki ilişki belirlenmiştir, öğrenci katılımları sınıf düzeyleri açısından karşılaştırılmıştır (Kahraman, 2014). Ayrıca literatür incelendiğinde öğrenci katılımını cinsiyet açısından inceleyen çalışmalara rastlanmaktadır (Kindermann, 2007; Rimm-Kaufman vd., 2015). Ayrıca bu çalışmalar içerik alanlarında genelleme yapmaktadır ve fen bilimlerine ya da matematiğe özgü değillerdir; bu nedenle öğrenci katılımındaki cinsiyet eşitsizlikleri daha fazla araştırma yapılmasını gerektirmektedir (Rimm-Kaufman vd., 2015:3). Ancak örneğin, fen ve mühendislik uygulamalarına katılım, kavram yanılgıları, tutumlar, cinsiyet ve kimlik sorunları gibi birçok faktör fen bilimlerine katılımı diğer alanlardan farklı şekilde etkileyebilir (Sinatra vd., 2015:4). Öğrencilerin katılımını ve onu etkileyen faktörleri anlamak, zorunlu eğitimden sonra fen ve matematiğin kavranmasını ele almak için de gereklidir (Hampden-Thompson and Bennett, 2013:20). Dolayısıyla Türkiye'de fen ve matematik derslerinde öğrenci katılımını belirlemeyi ve katılımı etkileyen faktörleri incelemeyi amaçlayan çalışmalara ihtiyaç duyulmaktadır.

$\mathrm{Bu}$ araştırmada ortaokul öğrencilerinin fen bilimleri ve matematik derslerine katılım düzeylerine ek olarak cinsiyet ve proje tasarlamada kendilerini yeterli görmeleri açılarından da incelenmiştir. Çünkü öğrenciler, proje tasarlama sürecinde hem sorunun hem de aktivitelerin oluşturulmasından ve doğasından sorumludurlar ve bu sorumluluklarından dolayı süreçte uzun süreli çaba göstererek aktif katılımları önemli görülmektedir (Blumenfeld vd., 1991:373). Bu nedenle öğrencilerin kendilerini proje tasarlayabilme konusunda yeterli hissetmeleri açısından öğrencilerin katılımlarının belirlenmesi fen bilimleri ve matematik başarısı için önemli görülmektedir. Buradan hareketle bu çalışma ile ortaokul ögrrencilerinin fen bilimleri ve matematik derslerine katılımlarını belirlemek ve cinsiyet, proje tasarlama öz-yeterlik algıları açısından incelemek amaçlanmıştır. Araştırmanın amacı doğrultusunda belirlenen alt problemler aşağıdaki gibidir:

Ortaokul öğrencilerinin fen ve matematik derslerine katılım düzeyleri nedir?

Ortaokul öğrencilerinin fen ve matematik derslerine katılım düzeylerinde cinsiyet açısından istatistiksel olarak anlamlı bir fark var mıdır?

Ortaokul öğrencilerinin fen ve matematik derslerine katılım düzeylerinde kendilerini proje tasarlamada yeterli görme durumları açısından istatistiksel olarak anlamlı bir fark var mıdır?

\section{YÖNTEM}

\section{Araştırmanın Modeli}


Araştırma, nicel araştırma yöntemlerinden tekil tarama ve nedenselkarşılaştırma araştırması kullanılarak yürütülmüştür (Fraenkel vd., 2012). Araştırmanın birinci alt problemine cevap aramak için tekil tarama yöntemi kullanılırken, ikinci ve üçüncü alt problemlerine cevap aramak için değişkenler açısından farklılıkların incelenmesi nedeni ile nedensel-karşılaştırma araştırma modelinden yararlanılmıştır. Nedensel karşılaştırmalı araştırmada, araştırmacılar, birey grupları arasında mevcut olan farklılıkların nedenlerini veya sonuçlarını belirlemeye çalışırlar (Fraenkel vd., 2012:12). Bu çalışmada da öğrencilerin matematik ve fen bilimleri derslerine katılımları cinsiyet ve kendilerini proje tasarlamada yeterli görme durumları değişkenleri açısından gruplandırılıp bu grupları karşılaştırmak amaçlandığından dolayı nedensel-karşılaştırma modeli kullanılmıştır.

\section{Araştırmanın Evren ve Örneklemi}

Araştırmanın evrenini Adıyaman ili Merkez ilçesinde 2019-2020 eğitimöğretim yılında öğrenim gören ortaokul 6., 7., ve 8. sinıf öğrencileri oluştururken örneklemini, uygun örnekleme yolu ile belirlenen iki ortaokulda öğrenim gören 320 öğrenci oluşturmaktadır. Uygun örneklem seçkisiz veya sistematik rastgele bir şekilde örnekleme yapmanın mümkün olmadığı durumlarda kullanılmaktadır (Fraenkel vd., 2012). Bu çalışmada da zaman, mekân ve ekonomik açıdan uygun olan örnekleme tercih edilmiştir. Örneklemin $155^{\prime}$ i kız öğrenciden ve 165 'i erkek öğrenciden oluşmaktadır. Ayrıca, öğrencilerin 116'sı 6. sınıfta, 80'i 7. sınıfta ve 124 'ü 8. sınıfta öğrenim görmektedir. Araştırmamızın verileri 2019 yılı içerisinde toplandığ 1 için bu dönemde etik kurul izni zorunlu olmadığ 1 için alınmamıştır.

\section{Veri Toplama Aracı}

Araştırmada veri toplama aracı olarak, Wang vd. (2016) tarafindan geliştirilen ve Turan Gürbüz vd. (2020) tarafından Türkçeye uyarlanan ve fen bilimleri dersi bağlamında geçerlik/güvenirlik çalışmaları yapılan Fen ve Matematik Dersi Katılım Ölçeği kullanılmıştır. Ölçek, 4 boyut ve 33 maddeden meydana gelmektedir. Bu boyutlar; bilişsel katılım, davranışsal katılım, duygusal katılım ve sosyal katılım şeklindedir. Turan Gürbüz vd. (2020)'nin çalışmalarında ölçeğin sadece fen bilimleri dersi kapsamında uyarlaması yapıldığı için bu çalışmada elde edilen verilere doğrulayıcı faktör analizi uygulanarak matematik dersi için de ölçeğin 4 faktörlü yapısı test edilmiştir. Yapılan doğrulayıcı faktör analizi sonuçlarına göre elde edilen uyum iyiliği indeksi değerleri $(\chi 2 / \mathrm{sd}=2.21$; RMSEA $=0.061 ; \mathrm{CFI}=0.96$; NFI $=0.92 ;$ NNFI: 0.95; $\mathrm{SRMR}=0.073 ; \mathrm{RMR}=$ 0.013) sonucunda ölçeğin 4 faktörlü yapısının kabul edilebilir düzeyde olduğu belirlenmiştir (Hu and Bentler, 1999; Tabachnick and Fidell, 2012). Dolayısıyla ölçeğin matematik dersine katılımı ölçmek için de kullanılmasına karar verilmiştir. Ölçeğin iç tutarlılık güvenirlik katsayısı 0.90 iken Guttman eşdeğer 
yarılar güvenirlik katsayısı 0.81 'dir. Bu çalışmada ise fen bilimleri dersi için ölçeğin iç tutarlılık güvenirlik katsayısı 0.91 , Guttman eşdeğer yarılar güvenirlik katsayısı 0.84; matematik dersi için ölçeğin iç tutarlılık güvenirlik katsayısı 0.90 iken Guttman eşdeğer yarılar güvenirlik katsayısı 0.81 olarak hesaplanmıştır.

\section{Verilerin Analizi}

Analiz aşamasında öncelikle veriler z değerlerine çevrilmiş ve -3’ten küçük, +3’ten büyük olan değerler uç değer olarak kabul edilerek veriler temizlenmiştir (Çokluk vd., 2010). Verileri temizleme işleme tamamlandıktan sonra daha sonra ölçekte yer alan madde puanlarının normal dağılım gösterip göstermediğini belirlemek amacıyla çarpıklık, basıklık katsayıları, mod, medyan, aritmetik ortalama değerleri ve histogram/Q-Q plot grafikleri incelenmiştir. Normallik dağglımları incelenirken her bir boyut için ve her bir bağımsız değişken için de boyutlar açısından ayrı ayrı incelenmiştir. Elde edilen bulgular doğrultusunda verilerin normal dağılım gösterdiği belirlenmiştir. Ölçek, beşli Likert tipinde olup Hiç katılımıyorum (1 puan) ile Tamamen katılıyorum (5 puan) arasında derecelendirilmektedir. Genel ölçek ortalamaları ve her bir ders için boyutların ortalamaları alınarak fark testleri uygulanmıştır. Ölçek 1 ile 5 arasında puanlandırıldığ için her aralık 4/5=.80 olarak alınmıştır. Dolayısıyla, 1-1.80: Hiç kat1lmiyorum, 1.81-2.60: Kat1lmiyorum; 2.61-3.40: Kismen kat1lyorum; 3.414.20: Kat1lyyorum; 4.21-5.00: Tamamen kat1lyyorum düzeyinde değerlendirilmiştir. $\mathrm{Bu}$ nedenle cinsiyet ve proje tasarlama öz-yeterliği değişkenleri açısından anlamlı bir farklılık olup olmadığını belirlemek amacı ile bağımsız t-testi kullanılmıştır. Sonuçlar yorumlanırken anlamlılık düzeyi.05 olarak alınmıştır. Yapılan fark testleri sonucunda istatistiksel olarak anlamlı çıkan bulguların pratikteki standart sapma değerini belirlemek amacıyla etki büyüklüğü değerleri hesaplanmışıır (Cohen, 2013). Bağımsız t testi kullanıldığı için etki büyüklükleri Cohen $\mathrm{d}$ değerleri hesaplanarak belirlenmiştir ve hesaplanan değerlerin değerlendirilmesinde Cohen (2013)'ün kriterleri baz alınmıştır ( $d \leq 0,2$ ise küçük, $0,2<\mathrm{d}<0,8$ ise orta ve $\mathrm{d} \geq 0,8$ ise geniş etki büyüklüğü).

\section{BULGULAR}

Araştırmanın alt problemleri doğrultusunda yapılan analizler bu bölümde sunulmuştur.

\section{Birinci Alt Probleme İlişkin Bulgular}

Araştırmanın birinci alt problemi "Ortaokul öğrencilerinin fen bilimleri ve matematik derslerine katılım düzeyleri nedir?” şeklindedir. Bu alt probleme cevap aramak için yapılan betimsel analiz sonuçları Tablo 1'deki gibidir. 
Tablo 1. Ortaokul Öğrencilerinin Fen Bilimleri ve Matematik Derslerine Katılım Düzeylerine İlişkin Analiz Sonuçları

\begin{tabular}{|c|c|c|c|c|}
\hline \multirow{3}{*}{$\begin{array}{c}\text { Fen } \\
\text { Bilimleri }\end{array}$} & & $\mathbf{N}$ & Ortalama & $\begin{array}{l}\text { Standart } \\
\text { sapma }\end{array}$ \\
\hline & Bilişsel & 320 & 3,63 & 61 \\
\hline & Davranışsal & 320 & 3,93 & ,73 \\
\hline \multirow{8}{*}{ Matematik } & Duyuşsal & 320 & 4,06 & ,73 \\
\hline & Sosyal & 320 & 3,85 & ,84 \\
\hline & Toplam & 320 & 3,89 & ,58 \\
\hline & Bilişsel & 320 & 3,60 & ,63 \\
\hline & Davranışsal & 320 & 3,95 & ,69 \\
\hline & Duyuşsal & 320 & 4,02 & ,80 \\
\hline & Sosyal & 320 & 3,84 & ,83 \\
\hline & Toplam & 320 & 3,87 & ,60 \\
\hline
\end{tabular}

Tablo 1 incelendiğinde ortaokul öğrencilerinin hem fen bilimleri dersine $(X=3,89)$ hem de matematik dersine $(X=3,87)$ katılım düzeylerinin katılıyorum seviyesinde olduğu belirlenmiştir. Veriler katılım boyutları açısından değerlendirildiğinde öğrencilerin her iki derste de duyuşsal katılım ortalamalarının en yüksek ve bilişsel katılım ortalamalarının en az olduğu belirlenmiştir.

\section{İkinci Alt Probleme İlişkin Bulgular}

Araştırmanın ikinci problemi "Ortaokul öğrencilerinin fen ve matematik derslerine katılım düzeylerinde cinsiyet açısından istatistiksel olarak anlamlı bir fark var mıdır?" şeklindedir. Bu probleme cevap aramak için bağımsız t-testi uygulanarak elde edilen sonuçlar Tablo 2'de sunulmuştur. 
$\underline{\text { S. Fırat-E. Acıkgül Fırat } \quad \text { Ortaokul Öğrencilerinin Fen Bilimleri ve... }}$

Tablo 2. Cinsiyet Açısından Bağımsız t Testi Sonuçları

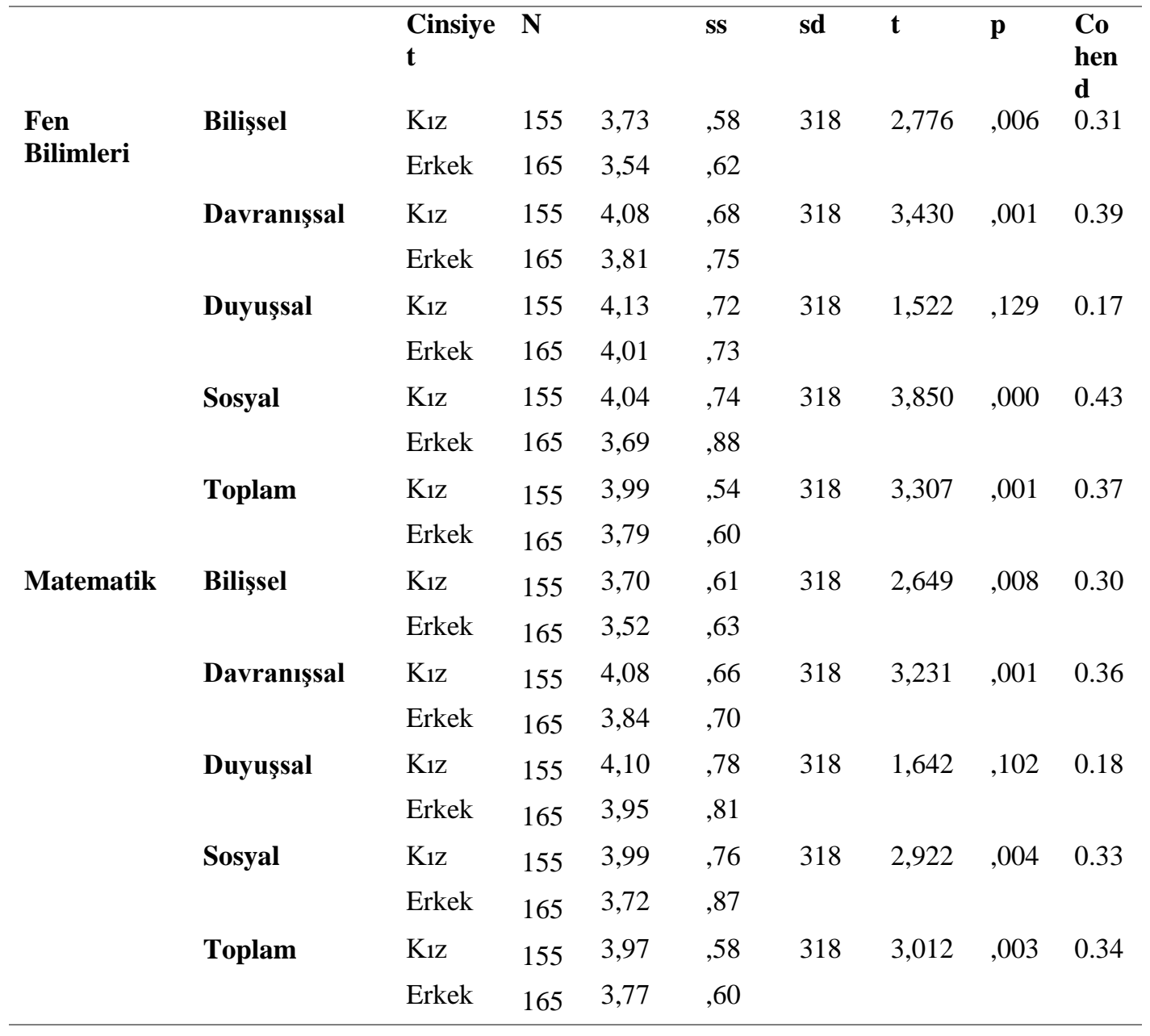

Tablo 2 incelendiğinde öğrencilerin fen bilimleri ve matematik derslerine katılım düzeyleri cinsiyet açısıdan her iki derste de kızların lehine anlamlı bir farkl111k göstermektedir (Fen Bilimleri: $\mathrm{t}=3,307 ; \mathrm{p}<0,05$; Matematik: $\mathrm{t}=3,012$; $\mathrm{p}<0,05)$. Hesaplanan Cohen $\mathrm{d}$ değerine göre her iki derste de kız ve erkek öğrenciler arasındaki farkın pratikte orta düzeyde bir etki değerine sahip olduğu belirlenmiştir (Cohen, 2013). Veriler katılım boyutları açısından incelendiğinde her iki derste de bilişsel, davranışsal ve sosyal katılımda cinsiyet açısından kızların lehine orta düzeyde etkiye sahip anlamlı bir farklılık olduğu tespit edilmiştir. Ancak duyuşsal katılımda her iki derste de cinsiyet açısından istatistiksel olarak anlamlı bir farkl111k bulunmamaktadır. 


\section{Üçüncü Alt Probleme İlişkin Bulgular}

Araştırmanın üçüncü alt problemi "Ortaokul öğrencilerinin fen ve matematik derslerine katılım düzeylerinde kendilerini proje tasarlamada yeterli görme durumlarıaçısından istatistiksel olarak anlamlı bir fark var mıdır?" şeklindedir. Yapılan bağımsız t-testi sonucunda elde edilen analiz sonuçları Tablo 3'de sunulmaktadır.

Tablo 3. Öğrencilerin Kendilerini Proje Tasarlamada Yeterli Görme Durumları Açısından Bağımsız t Testi Sonuçları

\begin{tabular}{|c|c|c|c|c|c|c|c|c|c|}
\hline & & Proje & $\mathbf{N}$ & & ss & sd & t & $\mathbf{p}$ & $\begin{array}{l}\text { Cohe } \\
\text { nd }\end{array}$ \\
\hline \multirow{10}{*}{$\begin{array}{l}\text { Fen } \\
\text { Bilimleri }\end{array}$} & \multirow[t]{2}{*}{ Bilişsel } & Evet & 107 & 3,75 & ,60 & 310 & 3,929 & ,000 & 0.45 \\
\hline & & Hayır & 201 & 3,59 & ,61 & & & & \\
\hline & \multirow{2}{*}{$\begin{array}{l}\text { Davra } \\
\text { nışsal }\end{array}$} & Evet & 107 & 4,10 & 67 & \multirow[t]{2}{*}{310} & \multirow[t]{2}{*}{4,095} & \multirow[t]{2}{*}{,00 } & \multirow[t]{2}{*}{0.47} \\
\hline & & Hayır & 201 & 3,89 & ,74 & & & & \\
\hline & \multirow{2}{*}{$\begin{array}{l}\text { Duyuşs } \\
\text { al }\end{array}$} & Evet & 107 & 4,14 & ,73 & \multirow[t]{2}{*}{310} & \multirow[t]{2}{*}{1,962} & \multirow[t]{2}{*}{,047 } & \multirow[t]{2}{*}{0.22} \\
\hline & & Hayır & 201 & 4,05 & ,73 & & & & \\
\hline & \multirow[t]{2}{*}{ Sosyal } & Evet & 107 & 3,99 & ,85 & \multirow[t]{2}{*}{310} & \multirow[t]{2}{*}{,742 } & \multirow[t]{2}{*}{,443 } & \multirow[t]{2}{*}{0.08} \\
\hline & & Hayır & 201 & 3,82 & ,83 & & & & \\
\hline & \multirow{2}{*}{$\begin{array}{l}\text { Topla } \\
\text { m }\end{array}$} & Evet & 107 & 4,00 & ,55 & \multirow[t]{2}{*}{310} & \multirow[t]{2}{*}{3,419} & \multirow[t]{2}{*}{,001 } & \multirow[t]{2}{*}{0.39} \\
\hline & & Hayır & 201 & 3,85 & ,59 & & & & \\
\hline \multirow{7}{*}{$\begin{array}{l}\text { Matemati } \\
\mathbf{k}\end{array}$} & \multirow[t]{2}{*}{ Bilişsel } & Evet & 107 & 3,70 & ,60 & \multirow[t]{2}{*}{310} & \multirow[t]{2}{*}{3,910} & \multirow[t]{2}{*}{,000 } & \multirow[t]{2}{*}{0.44} \\
\hline & & Hayır & 201 & 3,58 & 64 & & & & \\
\hline & \multirow{2}{*}{$\begin{array}{l}\text { Davra } \\
\text { nışsal }\end{array}$} & Evet & 107 & 4,10 & 63 & \multirow[t]{2}{*}{310} & \multirow[t]{2}{*}{4,032} & \multirow[t]{2}{*}{,000 } & \multirow[t]{2}{*}{0.46} \\
\hline & & Hayır & 201 & 3,91 & ,70 & & & & \\
\hline & \multirow{2}{*}{$\begin{array}{l}\text { Duyuşs } \\
\text { al }\end{array}$} & Evet & 107 & 4,08 & ,77 & \multirow[t]{2}{*}{310} & 2,497 & 013, & 0.28 \\
\hline & & Hayır & 201 & 4,04 & ,79 & & & & \\
\hline & Sosyal & Evet & 107 & 3,97 & ,85 & 310 & ,887 & 376, & 0.10 \\
\hline
\end{tabular}


$\underline{\text { S. Fırat-E. Acıkgül Fırat } \quad \text { Ortaokul Öğrencilerinin Fen Bilimleri ve... }}$

\begin{tabular}{lllllllll}
\hline & Hayır & 201 & 3,80 &, 82 & & & & \\
$\begin{array}{l}\text { Topla } \\
\text { m }\end{array}$ & Evet & 107 & 3,97 &, 56 & 310 & 3,616 &, 000 & 0.41 \\
& Hayır & 201 & 3,85 &, 61 & & & & \\
\hline
\end{tabular}

Tablo 3 incelendiğinde öğrencilerin fen bilimleri ve matematik derslerine katılım düzeylerinde kendilerini proje tasarlamada yeterli görme durumları açısından kendilerini yeterli hisseden öğrenciler lehine anlamlı bir farklılık olduğu belirlenmiştir. Ayrıca bu farklılığın her iki derste de orta düzeyde bir etkiye sahip olduğu belirlenmiștir (Cohen, 2013). Veriler katılım boyutları açısından incelendiğinde bilişsel, duyuşsal ve davranışsal boyutlarda her iki derste de orta düzeyde etkiye sahip olan anlamlı farklılıklar olduğu belirlenirken sosyal katılımda istatistiksel olarak anlamlı bir farklılık olmadığ belirlenmiştir.

\section{TARTIŞMA, SONUÇ VE ÖNERILER}

$\mathrm{Bu}$ araştırma ile ortaokul öğrencilerinin fen bilimleri ve matematik derslerine katılım düzeylerini belirlemek ve cinsiyet, kendilerini proje tasarlamada yeterli görme durumları değişkenleri açısından incelemek amaçlanmıştır. Mevcut araştırma öğrenci katılımını fen bilimleri ve matematik alanları bazında ve çok boyutlu ölçmesi açısından önemli görülmektedir. Araştırmadan elde edilen sonuçlara göre, ortaokul öğrencilerinin hem fen bilimleri dersine hem de matematik dersine katılım düzeylerinin katıllyorum seviyesinde olduğu belirlenmiştir. Elde edilen sonuçlara göre tüm katılım boyutlarında ortalamaların yüksek olduğu ve öğrencilerin fen ve matematik derslerine bilişsel, duygusal, davranışsal ve sosyal katılım sağladıkları belirlenmiştir. Bu verilerden hareketle, öğrencilerin fen ve matematik derslerinde öğretim sürecine çok boyutlu olarak katılım düzeylerinin yüksek olması ile akademik başarıları ve STEM başarılarının da sağlanabileceği söylenebilir (Fredricks vd., 2016a; Sinatra vd., 2015). TIMMS verileri incelendiğinde de 2019 yılında 8. Sinıf öğrencilerinin fen başarılarında 39 ülke arasından 15. sırada olup ölçek orta noktasının üzerindeyken ve matematik başarısı açısından 20. Sırada bulunmaktadır (TIMMS, 2019). Ayrıca, rapor incelendiğinde hem fen bilimleri hem de matematik başarılarının daha önceki yıllara göre daha yüksek düzeyde olduğu belirtilmiştir (TIMMS, 2019). Sonuçlar, katılım boyutları açısından değerlendirildiğinde öğrencilerin her iki derste de duyuşsal katılım ortalamalarının en yüksek ve bilişsel katılım ortalamalarının en az olduğu belirlenmiştir. Mo vd. (2013), fen bilimleri öğretiminde davranışsal katılımı vurgulamalarına rağmen bu çalışmada öğrenciler en fazla duygusal katılım gösterdiklerini belirtmişlerdir. Bilişsel katılım düzeylerinin her iki derste de en düşük ortalamaya sahip olması, literatürde bilişsel katılımın 
kavramsallaştırılması ve dolayısıyla ölçülmesinde problemlere neden olmasından kaynaklanabilir (Fredricks vd., 2016a). Çünkü bu problemler öğrencilerde de benzer şekiller de görülebilir ve kendilerini bilişsel açıdan değerlendirme konusunda sıkıntı yaşıyor olabilirler.

Araştırmadan elde edilen diğer bir sonuca göre öğrencilerin fen ve matematik derslerine katılım düzeyleri cinsiyet açısıdan her iki derste de kızların lehine anlamlı bir farkl111k göstermektedir ve bu farkl11ık pratikte orta düzeyde bir etki değerine sahiptir (Cohen, 2013). Sonuçlar, katılım boyutları açısından incelendiğinde her iki derste de bilişsel, davranışsal ve sosyal katılımda cinsiyet açısından kızların lehine orta düzeyde etkiye sahip anlamlı bir farklılık olduğu tespit edilmiştir. Ancak duygusal katılımda her iki derste de cinsiyet açısından istatistiksel olarak anlamlı bir farklılık bulunmamaktadır. Literatürde yer alan çalışmalarda benzer şekilde ortaokul öğrencilerinde erkekler kızlara göre daha düşük davranışsal katılım düzeyleri göstermektedir (Kindermann, 2007; RimmKaufman vd., 2015). Wang vd. (2011) de bu çalışma ile benzer şekilde çalışmalarında davranışsal ve bilişsel katılımda çalışmasında kız öğrencilerin erkekler öğrencilerden daha yüksek katılım düzeyine sahip oldukları belirlemişlerdir. Park (2005) ise öğrenci katılımının cinsiyetten bağımsız olarak matematikteki akademik kazanımlar üzerinde olumlu etkileri olduğunu belirtmiştir. Hampden-Thompson ve Bennett (2013) ise bu çalışmanın aksine, 15 yaşındaki öğrencilerle fen ve matematik okuryazarlı̆̆ını belirlemek amacı ile PISA sınav sonuçlarını kullanarak yaptıkları çalışmalarında erkeklerin kızlardan daha fazla katılım gösterdiğini belirtmişlerdir.

Araştırmadan elde edilen diğer bir sonuç hem matematik hem de fen bilimleri derslerinde genel katılımda ve bilişsel, duygusal ve davranışsal katılım boyutlarında proje tasarlamak konusunda kendilerini yeterli hisseden öğrencilerin anlamlı şekilde daha fazla katılım gösterdikleri belirlenmiştir. $\mathrm{Bu}$ sonuç, proje tasarlamada da gerekli olan küçük problem çözme gruplarında öğrencilerin geçirdikleri süre boyunca derse daha ilgili ve duyarlı olması ile açılanabilir (Uekawa vd., 2007). Yair (2000) de çalışmasında öğretmenlerin merkezde olduğu dersler yerine problem çözme stratejilerinin uyguladıkları derslerde öğrencilerin derse katılımının daha fazla olduğunu belirlemiştir. Çünkü ders anlatımının baskın öğretim modu olduğunda, sınıf öğrenimine aktif katılımdan caydırılabilecek düşük performans gösteren öğrenciler üzerinde güçlü ve olumsuz bir etkiye sahip olabilir. (Uekawa vd., 2007). Mevcut araştırma sonuçlarına göre sosyal katılım açısından kendini proje tasarlamada yeterli gören ve görmeyen öğrenciler arasında istatistiksel olarak anlamlı bir farklılık bulunmamaktadır. $\mathrm{Bu}$ sonuç öğrencilerin projeleri tasarlama sürecini grup çalışmasından ziyade bireysel olarak algılamalarından kaynaklanıyor olabilir. Uekawa vd. (2007) de çalışmalarında Asyalı öğrencilerin en çok bireysel çalışma 
sırasında meşgul olduklarını ve işbirlikçi bir ortamda katılımlarının daha düşük olduğu sonucuna ulaşmışlardır.

Sonuç olarak bu çalışma ile fen bilimleri ve matematik derslerinde öğrenci katılımlarının düzeyi çok boyutlu olarak belirlenmiş ve cinsiyet, kendilerini proje tasarlamada yeterli görme durumları faktörleri açısından incelenmiştir. Kahraman (2014) de çalışmasında davranışsal ve duyuşsal katılımın başarı üzerinde pozitif etkisi olduğunu belirtmiştir. Dolayısıyla öğrenci katılımının öğrencilerin okul başarısının önemli bir göstergesi olduğu (Rimm-Kaufman vd., 2015:3) düşünüldüğünde bu çalışmanın sonuçları literatüre katkıda bulunacaktır.

Yapılan çalışma sonucunda öğrenci katılımının, kendilerini proje tasarlamada yeterli gören öğrencilerde anlamlı bir şekilde daha fazla olduğu belirlenmesinden dolayı fen bilimleri ve matematik derslerinde STEM uygulamaları ile öğrencilerin proje tasarlama becerilerini geliştirecek ortamların düzenlenmesi önerilebilir. Ayrıca bu çalışmada proje tasarlama konusunda tek cevaplı bir soru ile öğrencilerin kendilerini yeterli hissedip hissetmedikleri belirlenmiştir. Yapılacak başka çalışmalar ile öğrencilerin proje tasarlama becerileri rubrikler aracılığıyla ölçülerek daha güvenilir sonuçlar elde edilebilir. Araştırmadan elde edilen diğer bir sonuç ise erkek öğrencilerin kızlara göre anlamlı bir şekilde daha düşük katılım sağlamalarıdır. Yapılacak çalışmalar ile bu durumun nedenleri araştırılarak fen ve matematik sınıflarında bu farklılığı gidermeye yönelik etkinlikler düzenlenebilir. Ayrıca çalışma farklı yaş gruplarındaki örneklemlerde yapılarak yaş değişkeni açısından karşılaştırma yapılabilir.

\section{KAYNAKÇA}

Axelson, R. D. and Flick, A. (2010). Defining student engagement. Change: The magazine of higher learning, 43(1), 38-43.

Azevedo, F. S., Disessa, A. A. and Sherin, B. L. (2012). An evolving framework for describing student engagement in classroom activities. The Journal of Mathematical

Behavior, 31(2), 270-289. https://doi.org/10.1016/j.jmathb.2011.12.003

Blumenfeld, P. C., Soloway, E., Marx, R. W., Krajcik, J. S., Guzdial, M and Palincsar, A. (1991). Motivating project-based learning: Sustaining the doing, supporting the learning. Educational psychologist, 26(3-4), 369398.

Bond, M., Buntins, K., Bedenlier, S., Zawacki-Richter, O. and Kerres, M. (2020). Mapping research in student engagement and educational technology in higher education: A systematic evidence map. International Journal of 
Educational Technology in Higher Education, 17(1), 2-30. https://doi.org/10.1186/s41239-019-0176-8

Bybee, R. W. (2013). The case for STEM education: Challenges and opportunities. NSTA press.

Cohen, J. (2013). Statistical power analysis for the behavioral sciences. Academic press.

Çokluk, Ö., Şekercioğlu, G. ve Büyüköztürk, Ş. (2010). Çok değişkenli istatistik SPSS ve LISREL uygulamaları (1. baskı). Pegem Akademi Yayınları.

DeVito, M. (2016). Factors Influencing Student Engagement [Unpublished Certificate of Advanced Study Thesis]. Sacred Heart University. Retrieved from http://digitalcommons.sacredheart.edu/edl/11

Fielding-Wells, J. and Makar, K. (2008, November 30-December 4). Student (dis)engagement in mathematics. Annual Conference of the Australian Association for Research in Education, Brisbane, Australia.

Fraenkel, J. R., Wallen, N. E. and Hyun, H. H. (2012). How to design and evaluate research in education. McGraw-hill.

Fredricks, J. A. (2011). Engagement in school and out-of-school contexts: A multidimensional view of engagement. Theory into practice, 50(4), 327335. https://doi.org/10.1080/00405841.2011.607401

Fredricks, J. A., Blumenfeld, P. C. and Paris, A. H. (2004). School engagement: Potential of the concept, state of the evidence. Review of educational research, 74(1), 59-109.

Fredricks, J. A., Wang, M. T., Linn, J. S., Hofkens, T. L., Sung, H., Parr, A. and Allerton, J. (2016a). Using qualitative methods to develop a survey measure of math and science engagement. Learning and Instruction, 43, 515. https://doi.org/10.1016/j.learninstruc.2016.01.009

Fredricks, J. A., Filsecker, M. and Lawson, M. A. (2016b). Student engagement, context, and adjustment: Addressing definitional, measurement, and methodological issues. Learning and Instruction, 43, 1-14. https://doi:10.1016/j.learninstruc.2016.02.002

Gürbüz, G. T., Açıkgül Fırat E. ve Aydın, M. (2020). Science Engagement Scale: Adaptation, Validation and Reliability Study. Adiyaman Üniversitesi Ë̆itim Bilimleri Dergisi, 10(2), $122-131$. https://doi.org/10.17984/adyuebd.670173 
Hampden-Thompson, G. and Bennett, J. (2013). Science teaching and learning activities and students' engagement in science. International Journal of Science Education, 35(8), 1325-1343. https://doi.org/10.1080/09500693.2011.608093

Hu, L. T. and Bentler, P. M. (1999). Cutoff criteria for fit indexes in covariance structure analysis: Conventional criteria versus new alternatives. Structural Equation Modeling: A Multidisciplinary Journal, 6(1), 1-55.

Kahraman, N. (2014). Öğrenci katılımı ve TIMSS 2011 fen başarısı arasındaki iliş̧inin sınıflara göre karşılaştırılması. Ĕgitim ve Bilim, 39(172), 95-107.

Kennedy, T. J. and Odell, M. R. L. (2014). Engaging students in STEM education. Science Education International, 25(3), 246-258.

Kindermann, T. A. (2007). Effects of naturally existing peer groups on changes in academic engagement in a cohort of sixth graders. Child Development, 78(4), 1186-1203.

Mo, Y., Singh, K. and Chang, M. (2013). Opportunity to learn and student engagement: A HLM study on eighth grade science achievement. Educational Research for Policy and Practice, 12(1), 3-19. https://doi.org/10.1007/s10671-011-9126-5

Park, S. Y. (2005). Student engagement and classroom variables in improving mathematics achievement. Asia Pacific Education Review, 6(1), 87-97.

Parsons, J. and Taylor, L. (2011). Improving student engagement. Current issues in education, 14(1), 1-33.

Rimm-Kaufman, S. E., Baroody, A. E., Larsen, R. A., Curby, T. W. and Abry, T. (2015). To what extent do teacher-student interaction quality and student gender contribute to fifth graders' engagement in mathematics learning?. Journal of Educational Psychology,107(1), 170-185. https://doi.org/10.1037/a0037252

Sinatra, G. M., Heddy, B. C. and Lombardi, D. (2015). The challenges of defining and measuring student engagement in science. Educational Psychologist, 50(1), $1-13$. https://doi.org/10.1080/00461520.2014.1002924

Tabachnick, B. G. and Fidell, L. S. (2012). Using multivariate statistics (6th ed.). Pearson. 
Uekawa, K., Borman, K. and Lee, R. (2007). Student engagement in US urban high school mathematics and science classrooms: Findings on social organization, race, and ethnicity. The Urban Review, 39(1), 1-43. https://doi.org/10.1007/s11256-006-0039-1

Wang, M. T. and Eccles, J. S. (2013). School context, achievement motivation, and academic engagement: A longitudinal study of school engagement using a multidimensional perspective. Learning and Instruction, 28, 1223. https://doi.org/10.1016/j.learninstruc.2013.04.002

Wang, M. T. and Holcombe, R. (2010). Adolescents' perceptions of school environment, engagement, and academic achievement in middle school. American educational research journal,47(3), 633-662. https://doi.org/10.3102/0002831209361209

Wang, M. T., Fredricks, J. A., Ye, F., Hofkens, T. L. and Linn, J. S. (2016). The math and science engagement scales: Scale development, validation, and psychometric properties. Learning and Instruction, 43, 16-26. https://doi.org/10.1016/j.learninstruc.2016.01.008

Wang, M. T., Willett, J. B. and Eccles, J. S. (2011). The assessment of school engagement: Examining dimensionality and measurement invariance by gender and race/ethnicity. Journal of School Psychology, 49(4), 465-480. https://doi.org/10.1016/j.jsp.2011.04.001

Yair, G. (2000). Educational battlefields in America: The tug-of-war over students' engagement with instruction. Sociology of education, 73(4), 247269.

Yerdelen-Damar, S., Korur, F. ve Sağlam, H. (2020). Matematik ve Fen Derslerine Katılım Ölçeğinin Fizik Dersi Bağlamında Türkçeye Uyarlanmas1. Turkish Journal of Educational Studies, 7(2), 1-15. https://doi.org/10.33907/turkjes.661339

Yıldırım, G., Sökmen, Y., Taş, Y. ve Dilekmen, M. (2018). Öğrenci Katılım Ölçeğinin Türkçeye Uyarlanması: Geçerlik ve Güvenirlik Çalışması. Trakya Üniversitesi Eğitim Fakültesi Dergisi, 8(1), 68-79. https://doi.org/10.24315/trkefd.364039 